El VÁter de LA ESCUELA. UnA REFLEXIÓN SOBRE GÉNERO, ARQUITECTURA Y EDUCACIÓN

The SCHOol tollet. Some CONSIDERATIONS ABOUt GeNDER, ARCHITECTURE AND

EDUCATION

\title{
Amelia Barquín
}

Mondragon Unibertsitatea, Facultad de Humanidades y Ciencias de la Educación; abarquin@mondragon.edu

\begin{tabular}{ll} 
& Resumen \\
\cline { 2 - 3 } $\begin{array}{l}\text { Palabras clave } \\
\text { Género }\end{array}$ & $\begin{array}{l}\text { En este texto reflexiono sobre un aspecto que apenas se ha debatido de modo pú- } \\
\text { blico en el mundo de la educación: el diseño y uso de los váteres escolares. Tanto } \\
\text { Arquitectura }\end{array}$ \\
Educación & pie (niño) / sentada (niña)". En el artículo analizo las razones de esta división así \\
Váter escolar & como sus consecuencias, y trato las resistencias de los varones ante el asiento. Por \\
& otro lado, abordo la actual separación de los retretes escolares por género y expon- \\
& go las implicaciones de este hecho, aludiendo en particular al alumnado discapaci- \\
& tado y al alumnado transexual. Explico, por último, la propuesta novedosa en este \\
& terreno de un centro escolar concreto que se encuentra en obras. El artículo está \\
destinado a personas interesadas en cuestiones de género, a profesorado en gene- & ral y a quienes se dedican a la arquitectura de espacios educativos.
\end{tabular}

Abstract

Keywords

Gender

Architecture

Education

Schooltoilet

Abstract: In this article I propose a topic rarely discussed publicly in education: the design and use of school toilets. Both at home and at school pupils learn to urinate according to the dichotomy "standing (boy) / sitting (girl)". I analyze the reasons for this division and its consequences, making reference to male resistance to the use of a seat, as a specific construct of masculinity. The text also addresses the separation of school toilets according to gender and points out the implications of this fact, referring in particular to disabled pupils and transgender students. Lastly I describe some new proposals in relation to this topic that are taking place in a school undergoing construction. The article is directed at those interested in gender issues, at educators in general, and at those involved with the architecture of public buildings and of educational facilities in particular.

Barquín, Amelia (2015). El váter de la escuela. Una reflexión sobre género, arquitectura y educación. Athenea Digital, 15(1), 303-315. http://dx.doi.org/10.5565/rev/athenea.1539

\section{Preguntas de partida}

A quienes tenemos la tarea de educar nos ha tocado en más de una ocasión acompañar al baño a nuestro alumnado de corta edad y hemos visto casi siempre que las niñas han aprendido a orinar sentadas y los niños, de pie. Pero no se trata únicamente de un aprendizaje que el alumnado ha realizado en casa; también muchas maestras y maestros de educación infantil (¿la gran mayoría?) siguen enseñando a hacer pis en la dicotomía "sentada (niña) /de pie (niño)".

¿Por qué? ¿Para qué se enseña así? Buena parte del profesorado al que he tenido ocasión de formular estas preguntas en escuelas del País Vasco muestra cierta sorpresa 
e indica no haber reparado hasta el momento en la cuestión. Otra parte, sin embargo, ha reflexionado sobre ella y tiene una práctica que pretende superar la dicotomía señalada. Este grupo comparte, además, experiencias muy interesantes; entre otras, la resistencia casi insuperable que muestran algunos niños pequeños a hacer pis sentados, y también las protestas de algunas madres y padres cuando se enteran de que sus hijos pequeños se sientan en el váter de la escuela.

Por otra parte está la cuestión de la separación habitual de los retretes, que también se produce en la escuela: unos son para chicos y otros son para chicas. Es otro aspecto sobre el que el profesorado en general no expresa disconformidad o análisis; resulta una práctica asumida como "natural" en el entorno educativo.

¿Podemos debatir sobre el uso de los váteres en la escuela o aquello que se refiere al cuerpo y en particular a los desechos que produce es todavía un tabú? Por mi parte, creo que en la escuela debe haber lugar para el cuerpo en su totalidad y que la cuestión que nos ocupa merece una reflexión y un tratamiento pedagógico consecuente.

Este artículo pretende ser una aportación es ese terreno y se dirige a cualquier persona interesada en el género, al profesorado en general, y también a quienes se dedican a la arquitectura de espacios educativos.

\section{Repensar el diseño de los váteres escolares. Un criterio básico}

En una escuela de educación infantil y primaria de Vitoria se está llevando a cabo una profunda obra de renovación, para la cual se ha contado con la opinión de la comunidad escolar. Entre otras cuestiones, se ha debatido sobre cuál deberá ser el diseño de los váteres, debate relacionado con la reflexión que está llevando a cabo el profesorado en torno al género y a su tratamiento en el centro. El debate es de gran interés, a la vez que poco frecuente. Raramente tiene una comunidad escolar la ocasión de decir algo en cuestiones de arquitectura puesto que en el diseño de los edificios no se suele consultar con ella. Pero además no todas las comunidades contarían con unos criterios concretos al respecto que proponer al equipo de arquitectura.

Uno de los criterios básicos para la obra en marcha es que los espacios contribuyan tanto a la igualdad de derechos de niñas y niños como al respeto y estima hacia la diversidad, también la diversidad de identidad en proceso de construcción del alumnado. El diseño arquitectónico tiene, sin duda, mucho que aportar en relación con este criterio, aunque a menudo no se presta la atención suficiente a la contribución que pueden hacer los aspectos arquitectónicos. Ya hemos aprendido que el patio de la es- 
cuela no puede ser únicamente un campo de fútbol para los niños que juegan bien a este deporte mientras que el resto de los niños y casi todas las niñas se conforman con ocupar los márgenes (Subirats y Tomé 2007), pero quedan aún muchos espacios escolares por repensar. Los váteres no deberían ser una excepción en este sentido, sino todo lo contrario. No hay que olvidar, por otro lado, que junto al componente funcional de ese recinto se encuentra el simbólico, de no poca importancia en este caso, como veremos.

Los elementos de debate en el centro escolar citado han sido dos. Uno de ellos es si el profesorado de infantil debe enseñar a su alumnado a hacer pis en la lógica binaria "de pie (niño) / sentada (niña)" o debe superarla. El otro es si debe seguir habiendo espacios separados: "el váter de las chicas y el váter de los chicos".

\section{La necesidad de superar la lógica binaria del género}

Beatriz Preciado (2006) explica cómo una arquitectura que parece simplemente ponerse al servicio de las necesidades naturales más básicas llega a operar como una sumamente discreta y efectiva tecnología constructora de género.

Recordemos, antes que nada, que el género es una construcción social y cultural. Tras clasificar a las personas en dos sexos, se adjudica a cada uno de ellos un conjunto de formas de ser y de comportarse, repertorio que constituye el género y que se adquiere a través de la socialización. A esa socialización en dos géneros contrapuestos contribuyen las familias, la escuela, la religión, los medios de comunicación, los productos culturales...

Marina Subirats, autora de un estudio clásico sobre coeducación (Subirats y Brullet 1988), explica la necesidad de superar las restricciones que implica criar(se) y educar(se) en dos géneros. Los géneros, señala, "tienen que desaparecer en tanto que modelos de comportamiento y de acción impuestos por la sociedad, obligatorios para los individuos en función de su sexo" (Subirats, 2013, p. 184). Tal y como la autora señala,

Lo que no tiene sentido es que la agresividad sea prescrita a los muchachos por el hecho de serlo, esté o no en su naturaleza y en su voluntad; y la ternura y la empatía en las muchachas, aunque no vaya con ellas. Cada ser humano debe ser libre para elegir aquellas actitudes que le son afines [...]. Cada ser humano debe poder combinar las antiguas características femeninas y masculinas que habitan en él o en ella, y poder hacerlo desde la libertad, en las dosis y las circunstancias que le parezcan más convenientes. (p. 185). 
Son muchas las voces que tanto desde la educación como desde otros terrenos propugnan que "los seres humanos sean lo que quieran ser y vivan como quieran vivir, sin un destino marcado por el sexo con el que hayan nacido" (Varela, 2008, p. 20). Por su parte el desarrollo de la teoría Queer ofrece marco teórico a la utopía de un mundo de personas libres de etiquetas que construyen libremente sus identidades, más allá del sexo que a cada una le fue asignado al nacer.

El sistema escolar en general y cada docente en particular tiene aún por delante mucha reflexión en el terreno de la construcción del género, que ha de partir seguramente de la autoconciencia sobre en qué medida reproduce cada cual las presiones de género sobre el alumnado, o, por el contrario, contribuye al libre desarrollo de las personas.

\section{Los retretes públicos como instrumentos de construcción del género}

Los retretes públicos (de un bar, un cine...) y el retrete de casa no son iguales. En las casas suele haber una sola habitación para evacuar, que habitualmente contiene un único inodoro, utilizado para hacer tanto pis como caca por cualquier persona. En los retretes públicos, sin embargo, hay dos espacios, uno para mujeres y otro para hombres. Los espacios son, además, diferentes. Las mujeres utilizan el inodoro (que es un espacio privado) para las dos funciones. El espacio compartido es el del lavabo y el espejo. En el retrete masculino los hombres utilizan el inodoro (espacio privado) para defecar, y el urinario de pared (que está en el espacio compartido, junto con el lavabo y el espejo) para orinar. En muchas escuelas el váter es semejante al de la casa, pero en la mayoría es más parecido al de los lugares públicos.

En el interesante análisis de Beatriz Preciado (2006) sobre los retretes públicos, se explica claramente cómo además de ser espacios para deshacerse de los residuos corporales, son cabinas de vigilancia del género.

En la puerta de cada retrete, como único signo, una interpelación de género: masculino o femenino, damas o caballeros, sombrero o pamela, bigote o florecilla, como si hubiera que entrar al baño a rehacerse el género más que a deshacerse de la orina y de la mierda. (Preciado, 2006, párrafo 3).

Pone como ejemplo los baños de señoras de un aeropuerto, donde la usuaria puede inspeccionar cada cuerpo que cruza el umbral y evaluar su aspecto. Cualquier ambigüedad de género (pelo demasiado corto, ausencia de maquillaje, paso firme...) puede 
llevar a la usuaria a indicar a la otra persona que se ha confundido de lugar y a expulsarla de él, con ayuda de la autoridad si es necesario.

Mientras que las mujeres hacen en el espacio privado las dos funciones y las llevan a cabo sentadas, en el caso de los hombres se separan las funciones (genital y anal): orinan de pie en el urinario accesible a la mirada pública, y defecan en el inodoro en un espacio privado donde el ano se oculta a la mirada.

Mear de pie es una de las performances constitutivas de la masculinidad heterosexual moderna. [...] los urinarios no están enclaustrados en cabinas opacas, sino es espacios abiertos a la mirada colectiva, puesto que mear-de-pieentre-tíos es una actividad cultural que genera vínculos de sociabilidad compartidos por todos aquellos que, al hacerlo públicamente, son reconocidos como hombres. (Preciado, 2006, párrafo 7).

Concluye Preciado que "cada momento de expulsión de un desecho orgánico sirve como ocasión para reproducir el género" (Preciado, 2006, párrafo 13).

\section{El váter de casa y el de la escuela}

En cualquier caso, los niños hacen pis de pie tanto en la escuela como en casa, tal y como lo hacen en los lugares públicos que tienen urinario de pared, aunque en el váter de casa no haya ese urinario y la distancia del pene hasta la taza sea mucho mayor. Orinar de pie en la taza de casa supone necesariamente que los hombres ensucian ese espacio, mucho o poco. No he olvidado un experimento que presencié en una sesión formativa: tras llenar una botellita (con embocadura para chupar que permite emitir un chorro continuo) con agua teñida de azul, se dirigió el chorro a la taza desde la altura del pubis. Gracias al color azul, quienes estábamos allí pudimos ver lo que el color claro de la orina no permite apreciar: hasta dónde llegaban a salpicar las pequeñas gotas, aunque se había puesto en práctica la mejor puntería. Asimismo los niños, a pesar de que lo hagan desde una distancia corta y tengan buen tino, envían una miríada de pequeñas gotas a todos los puntos del inodoro, también a lugares donde no llegará el agua tras dar la bomba.

Y, a pesar de todo, en la escuela seguimos enseñando a los niños pequeños a hacer pis de pie, como lo harán en los lugares públicos (el bar, el museo, quizá el trabajo...), pero no les enseñamos a adaptarse a los váteres más comunes (el de casa, en concreto, que será el que seguramente más utilizarán en adelante).

Quisiera añadir que la necesidad de intimidad es, precisamente, otro aspecto que tener en cuenta en el diseño de los váteres públicos y de los de la escuela en concreto. 
Beatriz Gimeno (2012) explica que también entre los chicos puede existir la preferencia de orinar sin compañía, lejos de la mirada de otros chicos y libres de las comparaciones. No son pocos los hombres que prefieren usar el cubículo con puerta a utilizar los urinarios de pared.

\section{¿De dónde procede la resistencia?}

¿De dónde procede la enorme resistencia de algunos niños pequeños y la protesta de algunos padres y madres ante la posibilidad de orinar sentados? La relación con la masculinidad hegemónica - que implica la posición dominante de los hombres sobre las mujeres- es clara (sobre la masculinidad hegemónica, véase Connell, 2003, pp. 116118). En nuestra sociedad hacerlo sentado es una característica femenina, y que los hombres hagan cosas propias de mujeres o al estilo de las mujeres supone para ellos una pérdida de prestigio, ya que lo femenino tiene menor estatus que lo masculino en nuestra sociedad. Junto al temor a "afeminarse", está el de "amariconarse", es decir, no parecer suficientemente masculino o parecer gay. Élisabeth Badinter señaló que la identidad masculina se construye sobre varias oposiciones o negaciones, entre las cuales está la de no ser mujer y la de no ser homosexual (1993, p. 51). El matiz de la apariencia es importante. Como señala Óscar Guasch (2013),

El problema no es tanto ser gay como parecerlo. Hay niños afeminados que nunca serán homosexuales pero que son tratados como si lo fueran. Y a lo mejor algunos que lo son pero no lo aparentan pueden sobrevivir mejor en la escuela (p. 53).

\section{La clave de la masculinidad}

Se puede señalar, además, otro componente claro, unido al imaginario de la masculinidad convencional. Sentarse es inclinarse, mostrarse manso y domado, reparar en las consecuencias, amoldarse a las normas, tener en cuenta la limpieza, manifestar consideración por quienes vendrán detrás... Hacerlo de pie se relaciona con el orgullo, la fuerza, con no mostrarse manso ni humilde y con estar despreocupado de las consecuencias, estar por encima de las normas, no tener en cuenta la limpieza, no cuidarse de quiénes vendrán detrás...; ser, en fin, un macho, o un macho "tradicional", si se quiere (Barquín, 2013). Ambas representaciones se corresponden con las formas contrapuestas de ser y de comportarse asignadas al género femenino y al masculino, tan en vigor aún hoy, a pesar de que los géneros no son funcionales, no ayudan a vivir, o, como explica gráficamente Marina Subirats (2013, pp. 167-168), están obsoletos. 
Esa visión de lo masculino que hemos indicado se percibe en las quejas de algunos hombres cuando se debate en la red la cuestión de orinar sentado, y que se resumen en "era lo que nos faltaba. Las mujeres nos lo quieren quitar todo y nos van a humillar hasta el final, hasta hacer incluso desaparecer nuestra masculinidad". Parecería, de hecho, que orinar de pie se hubiese convertido en el último reducto de la masculinidad tradicional.

Vaya por delante que no veo nada en contra de tener una actitud orgullosa: cada cual ha de ver qué actitud presenta al mundo. Sí creo, sin embargo, que esa actitud vital y el modo de usar el retrete no tienen relación directa o no tienen por qué tenerla.

La masculinidad hegemónica se encarna en ritos como el que estamos tratando. Algunos padres y madres y parte del profesorado son guardianes de esa masculinidad, con distintos niveles de (in)consciencia, en esta área igual que en otras áreas en relación con la educación. De ese modo se explica que los niños y los jóvenes sigan aprendiendo a orinar de pie y lo hagan así en su casa y en la escuela, sin reparar en las consecuencias. No está de más recordar que todavía hoy son más las mujeres que se encargan de la limpieza que los hombres que lo hacen. Entre los hombres que sí realizan tareas de limpieza hay seguramente, como es comprensible, un mayor número de ellos que han adaptado sus comportamientos para no ensuciar.

\section{Las mujeres también han orinado de pie}

¿Es "natural” la diferencia de género a la hora de usar el váter? La costumbre de utilizar ropa interior, al menos, es relativamente reciente en las clases bajas. El historiador Jose Antonio Azpiazu explica las costumbres en torno a la ropa y la higiene en el País Vasco y también cómo han cambiado en unas pocas décadas. Señala, entre otras cosas, lo siguiente: "hace 150-200 años, las bragas era muy curiosas. Cerradas en la cintura y abiertas en la zona de la vulva [...]. Las mujeres no se quitaban la braga para hacer pis. Nuestras abuelas hacían pis de pie” (Azpiazu, 2012, p. 7. La traducción es mía).

El no llevar braga y orinar de pie en el campo o en el establo abriendo un poco las piernas bajo la falda es algo que yo misma he visto entre mujeres rurales de Cantabria de bastante edad. No tengo referencias sobre el comportamiento en otras sociedades que mantienen la agricultura tradicional, pero es posible que pervivan costumbres semejantes.

No hay que olvidar, además, que el formato de los retretes en otros países es distinto del que conocemos aquí. Es el caso de los retretes públicos en China, por ejemplo, en muchos de los cuales la privacidad es menor que aquí para las dos funciones, 
tanto en el caso de las mujeres como en el de los hombres, ya que las personas usuarias pueden verse la parte superior del cuerpo entre sí.

Con esto quiero decir que, antes de que los váteres que usamos se extendieran en nuestra sociedad, los modos de orinar no eran los de hoy. Las costumbres actuales son construcciones sociales, adaptadas a los diseños concretos de unos espacios y unos instrumentos. No han sido siempre así y no tienen por qué serlo en adelante.

Es cierto que para hacer pis en una taza de váter, los niños pequeños necesitan un breve proceso de aprendizaje, para orientar el pene hacia abajo, por ejemplo. Pero también las niñas necesitan un aprendizaje para sentarse en el centro y que el líquido no caiga fuera. Es decir: la actividad no es "más natural" para ellas que para ellos; tanto unos como otras tienen que aprender.

\section{Un ejemplo literario: el cuento Yo lo hago sentado ¿Yqué?}

En algunos lugares del norte de Europa, en Alemania o en Escandinavia, por ejemplo, está más extendida que en nuestra sociedad la costumbre de que los hombres orinen sentados. Han puesto en marcha incluso algunas campañas para extender ese uso en lugares públicos; en los váteres de las casas se pueden encontrar advertencias para recordárselo tanto a los que viven en ella como a las visitas.

Todavía estamos lejos de estos casos. Como ejemplo me referiré al cuento titulado Yo lo hago sentado ¿Y qué?, de Arantza Iturbe (2005). El libro pertenece a la colección “Y qué?”; sus protagonistas tienen características "infrecuentes” y aprenden a salir adelante a pesar de las trabas que encuentran en la sociedad. Se puede decir que es una colección a favor de la diversidad.

La historia es la siguiente: el protagonista, Jesús, hace pis sentado, como su madre y no como su padre. De hecho, "Papá lo hace de pie. A medio metro de la taza del váter, y, casi siempre, la mitad cae fuera" (Iturbe, 2005, p. 18) para disgusto de la madre, que se lo reprocha a menudo.

Cuando sus tres amigos Unai, Manu y Javi le ven sentado en la escuela, se lo cuentan al resto de la clase y tiene que sufrir las risas de casi todo el grupo precisamente porque lo hace como las niñas. Entre otras, le repiten la cantinela "iJesús mea sentado! ¡Marichica-chica-chica!” (Iturbe, 2005, p. 16).

El protagonista lo pasa mal. Sus padres no le dan ningún consejo, pero su madre le había enviado antes del conflicto este mensaje ambivalente: “ $¡ Y$ mira que mamá me 
había avisado: Jesús, cariño, a mí me parece muy bien que te sientes en la taza, pero, ¿no sería mejor que aprendiera a hacerlo como papá?“ (Iturbe, 2005, p. 18).

Al final del cuento, Jesús encuentra una solución de compromiso: ha aprendido a hacerlo de pie, "pero sólo lo hago de pie en la escuela o donde haya gente. Cuando estoy solo o en casa, sigo meando sentado" (Iturbe, 2005, pp. 26-27).

El cuento acaba con las palabras siguientes: "Ahora, en la escuela, hago pis como papá y, en casa, como mamá. Y lo que es pensar, también pienso muchísimo. Además, sentado se piensa mejor, y, sobre todo, ensucia uno menos” (Iturbe, 2005, p. 30).

En resumen: el niño prefiere mear sentado y tiene buenas razones para hacerlo, pero ha decidido disimular y actuar en el espacio público como se espera de un varón convencional. ¿Dónde queda el lema “¿Y qué?” y la defensa de la diversidad? ¿Tan grande es la presión sobre los niños que el protagonista no se puede saltar esa norma ni en el mundo de la fantasía, a pesar de la exigencia del formato? La masculinidad hegemónica resulta, en fin, una verdadera carga.

\section{El váter para quienes usan silla de ruedas}

En el caso de las personas con movilidad restringida no se llevan a cabo clasificaciones de género rigurosas a la hora de usar el retrete. Para ellas hay un solo baño en la mayoría de los lugares, para hombres y mujeres. Y suele suceder que es el mismo que el baño de las mujeres (donde también se encuentra a menudo la plataforma para cambiar pañales). Puede entenderse como una solución pragmática, un modo de ahorrar recursos por la menor cantidad de personas que lo utilizarán, pero al mismo tiempo permite percibir que clasificar genéricamente a quienes tienen discapacidad no se considera tan importante. ¿Por qué? La respuesta puede ser que no se las ve como seres sexuados. Su discapacidad se coloca en primer - ¿único?- plano.

Paco Guzmán y Raquel Lucas Platero han hablado del conjunto de estereotipos que se construyen en torno a la persona con discapacidad, en el área de la sexualidad concretamente: que carece de instinto sexual, que no es atractiva o deseable, que no es apta para las relaciones sexuales, que será eternamente infantil... El sexo se representa como tabú en su caso. Efectivamente, tal y como Guzmán y Platero explican, estos prejuicios "presionan para que renuncie a sí misma y trate de ser lo que la sociedad espera de ella: un ser asexual” (Guzmán y Platero, 2012, p. 146)

Que el váter para personas en silla de ruedas -sean mujeres u hombres- sea el femenino, confirma la tesis de Preciado en torno al hecho de que los váteres son eficaces 
herramientas de construcción del género. Con las personas discapacitadas no sería necesaria la clasificación binaria estricta, en la medida en que se las ve como asexuadas.

Por otra parte, que a menudo el baño para personas con silla de ruedas sea el mismo que el de las mujeres y que no sea el de hombres, confirma al mismo tiempo la concepción del género masculino como el género por excelencia; al resto -mujeres en general, niños, personas discapacitadas - se les designa el otro espacio. Ese otro espacio, además, está relacionado semánticamente con lo delicado, con el cuidado (con quien cuida y con quien necesita cuidado).

\section{La clasificación de los niños y niñas transexuales}

Que los retretes escolares tal y como están diseñados hoy en día son una herramienta de construcción de los géneros, queda claro, además, en los conflictos que surgen en relación con las niñas y niños que no se identifican con el sexo que se les ha asignado médica y socialmente.

La situación de Coy Mathis, de seis años, nacida con pene y que se identifica a sí misma como niña, saltó a los medios de comunicación en junio de 2013 cuando, después de que la dirección de su escuela le prohibiera utilizar el váter de chicas, sus padres llevaran el caso a los tribunales, por entender que se estaban infringiendo los derechos de su hija (Véase García, 2013).

Por otra parte, la fiscalía superior de Andalucía decidió investigar en octubre de 2013 el trato recibido en sus escuelas por tres niños y niñas que se identifican con un género distinto del asignado (de seis, ocho y nueve años). El objetivo fue analizar si en esos centros se hizo caso a la solicitud de las familias de que se les llamara con el nombre que habían adoptado y se aceptara la ropa o el uniforme así como el uso del retrete correspondiente a la identidad elegida (Véase Rincón, 2013).

Como vemos, desde distintas instancias de la comunidad escolar se concede una enorme importancia al uso de los váteres según el género. No sólo por parte de las niñas y niños mencionados, sino por parte de sus familias, que apoyan su elección, y por parte de las autoridades escolares, que les niegan esa elección e insisten en prescribirles el retrete que les corresponde según el sexo que se les asignó en su nacimiento.

Que existan retretes separados para chicas y chicos implica que cada cual ha de autoclasificarse o definirse como hombre o mujer varias veces al día, cada vez que lo usa. Suele también implicar que el resto del alumnado y del profesorado y, tal y como hemos visto, sobre todo la dirección del centro, tienen autorización para juzgar si esa 
autoclasificación está "bien hecha" según las convenciones del binarismo hombre/mujer, así como para expulsar y enviar al otro retrete a la persona transgresora, con el claro mensaje de "tú no puedes elegir quién eres; debes ajustarte al sexo y al género que los expertos te asignaron al nacer”. Los váteres separados, por tanto, son actualmente reflejo del binarismo tradicional a la vez que eficaz herramienta reproductora de ese binarismo. Beatriz Gimeno (2012) ha señalado, por su parte, la incomodidad, el malestar, e incluso el peligro que hoy por hoy supone el uso de los váteres públicos para las personas adultas transexuales.

¿Es necesario que esto sea así? ¿No es mejor buscar alternativas más saludables que contribuyan a la construcción de la identidad fuera de presiones de género?

\section{Los criterios propuestos por el centro escolar}

En el centro escolar que mencionábamos al principio del artículo se han tomado una serie de decisiones con respecto al diseño de los váteres tras establecer algunos criterios básicos. ¿Cuáles son esos criterios?

1. Que en la etapa de educación infantil el profesorado enseñe a los niños y niñas a orinar desde la posición de asiento. Se compartirá este criterio con las familias (aunque se cuenta con que una parte de ellas actúe en casa de otro modo).

2. Que nadie tenga que definirse como mujer u hombre a la hora de usar el retrete y, por consiguiente, que nadie reciba un juicio o sea expulsado del espacio por otras personas que consideran que no le corresponde.

3. Que haya un dispositivo para los chicos que orinen de pie, de manera que no lo hagan de pie en los inodoros de asiento y no los ensucien.

4. Que el alumnado usuario pueda servirse del retrete en privacidad, no en un espacio compartido (tanto para hacer pis como caca, tanto de pie como sentado, sin importar la identidad de cada cual).

5. Que el espacio sea seguro. Como es sabido, los retretes son uno de los lugares donde más agresiones se producen en los centros: violencia de género, violencia homófoba, episodios de bullying... También el diseño del espacio debe contribuir a que no ocurran estos episodios.

El nuevo diseño respondería, por tanto, a este conjunto de criterios. Se prevé, por tanto, que no habrá lugares separados por géneros, sino que lo que el alumnado encontrará al entrar en el váter serán varias cabinas individuales, con puerta, equipadas 
bien con inodoro bien con urinario, que cada cual elegirá. Los váteres para personas con movilidad restringida no estarán, por tanto, en un espacio catalogado como femenino. El entorno común -el de los lavabos- no tendrá recovecos ni rincones ocultos, de modo que se facilite que las personas usuarias se sientan seguras.

Seguramente hay otros criterios posibles y otras propuestas arquitectónicas. Valga esta experiencia como ejemplo de una reflexión interesante y poco frecuente por parte de un centro escolar, que podría convertirse en referencia para otros.

\section{Referencias}

Azpiazu, Jose Antonio (2012, 14 de noviembre). Bainuontziak zertarakoer abili ez zekiten arbasoek, letxugak landatzen zituzten han. Elkarrizketa. Goiena. Extraído de http://goiena.net/albisteak/jose-antonio-azpiazu-bainuontziakzertarako-erabili-ez-zekiten-arbasoek-letxugak-landatzen-zituzten-han/

Badinter, Élisabeth (1993). XY: La identidad masculina. Madrid: Alianza Editorial.

Barquín, Amelia (2013). Baina mutilek pixa eserita egin dezakete? Maskulinitateaz gogoeta bat. HikHasi, 183, 33-35.

Connnell, Raewyn (2003). Masculinidades. México: Universidad Nacional Autónoma de México.

García, Carolina (2013, 13 de junio). Una niña transexual de seis años gana una demanda civil en Colorado. El País. Extraído de http://sociedad.elpais.com/sociedad/2013/06/24/actualidad/1372103107 547123 html

Gimeno, Beatriz (2012). ¿En qué váter entramos? Pikara magazine. Extraído de http://www.pikaramagazine.com/2012/07/\%C2\%BFen-que-vater-entramos/

Guasch, Óscar (2013). Ser macho mata. Pikara, 1, 51-54.

Guzmán, Paco y Platero, Raquel (Lucas) (2012). Passing, enmascaramiento y estrategias identitarias: diversidades funcionales y sexualidades nonormativas. En Raquel (Lucas) Platero (Ed.), Intersecciones: cuerpos y sexualidades en la encrucijada (pp. 125-158). Barcelona: Bellaterra.

Iturbe, Arantza (2001/2005). Yo lo hago sentado ¿Y qué? (Con ilustraciones de Jokin Mitxelena). Barcelona: La Galera.

Preciado, Beatriz (2006). Basura y género. Mear/ Cagar. Masculino/ Femenino. Extraído de www.hartza.com/basura.htm

Rincón, Reyes (2013, 2 de febrero). La fiscalía investiga el trato dado en tres colegios a niños transexuales. El País. Extraído de http://sociedad.elpais.com/sociedad/2013/10/02/actualidad/1380744087 194953 $\underline{\text { html }}$

Subirats, Marina (2013). Forjar un hombre, moldear una mujer. Girona: Aresta Mujeres.

Subirats, Marina y Brullet, Cristina (1988). Rosa y azul. La transmisión de los géneros en la escuela mixta. Madrid: Ministerio de Cultura e Instituto de la Mujer. 
Subirats, Marina y Tomé, Amparo (2007). Balones fuera. Reconstruir los espacios desde la coeducación. Barcelona: Octaedro.

Varela, Nuria (2008). Feminismo para principiantes. Barcelona: BSA.

\section{(c) \\ Este texto está protegido por una licencia Creative Commons 4.0.}

Usted es libre para Compartir — copiar y redistribuir el material en cualquier medio o formato- $\mathrm{y}$ Adaptar el documento - remezclar, transformar y crear a partir del material — para cualquier propósito, incluso comercialmente, siempre que cumpla la condición de:

Atribución: Usted debe reconocer el crédito de una obra de manera adecuada, proporcionar un enlace a la licencia, e indicar si se han realizado cambios . Puede hacerlo en cualquier forma razonable, pero no de forma tal que sugiera que tiene el apoyo del licenciante o lo recibe por el uso que hace. 